\title{
Entrepreneurial propensity for market analysis in the time of COVID-19: benefits from individual entrepreneurial orientation and opportunity confidence
}

\author{
Amir Emami ${ }^{1}$ D $\cdot$ Shayegheh Ashourizadeh ${ }^{2} \mathbb{D} \cdot$ Shima Sheikhi $^{1}$. \\ Gadaf Rexhepi ${ }^{3}$ (D)
}

Received: 4 April 2021 / Accepted: 12 October 2021 / Published online: 11 November 2021

(c) The Author(s), under exclusive licence to Springer-Verlag GmbH Germany, part of Springer Nature 2021

\begin{abstract}
This paper illustrates nascent entrepreneurs' decision-making process during the COVID-19 pandemic and sheds light on determinants and mechanisms of entrepreneurial action. It examines the mediating role of opportunity confidence in the relation between the individual entrepreneurial orientation and the entrepreneurial propensity for market analysis (EPMA). Furthermore, it investigates the moderating role of entrepreneurship entry mode (opportunity vs. necessity) concerning our research model. Applying the theory of reasoned action (TRA), we could verify the mediating role of opportunity confidence. The findings also show that the impact of individual entrepreneurial orientation on EPMA and opportunity confidence is independent of entrepreneurial entry mode. In contrast, entrepreneurial entry mode can moderate the relation between opportunity confidence and EPMA. Results are discussed and research implications are provided.
\end{abstract}

Keywords COVID-19 crisis · Entrepreneurial orientation · Entrepreneurial propensity for market analysis · Nascent entrepreneur $\cdot$ Necessity and opportunity entrepreneurship · Opportunity confidence

Mathematics Subject Classification 62J05 · 62J10 · 97K40

\section{Introduction}

The COVID-19 pandemic has burdened almost all countries with an unprecedented economic crisis and recession (GDA 2020). Based on previous experiences, organizations are not able to address all victims' needs in the time of a crisis (Schneider 1992, 2008). When formal organizations and governors fail to meet these

Amir Emami

a.emami@khu.ac.ir

Extended author information available on the last page of the article 
needs, individuals and groups of normal people take action to address this problem (Drabek 1987; Drabek and McEntire 2002; Kapucu et al. 2009; Shepherd 2020). These people are entrepreneurs who undertake a complicated string of tasks executed in several single steps during which the world does not stand still (Dimov and Pistrui 2020).

Recessions are detrimental, but they can provide opportunities in an innovative way (Ionescu-Somers 2020) and inevitably bring about changes in the market. At times of crises, like the COVID-19 pandemic, the changes in the entrepreneurial environment are even more sweeping which consequently leads to a substantial increase in the level of uncertainty that can be daunting entrepreneurs (McMullen and shepherd 2006; Block and Sandner 2009; Packard et al. 2017). Uncertainty, that is an inextricable part of the entrepreneurship ecosystem, has been exacerbated during the COVID-19 crisis.

Perceiving a higher market and operational uncertainty, nascent entrepreneurs -who are individuals in the process of creating a new venture in the conception or gestation phase- (Reynolds et al. 2000) may lose their willingness to become involved in creating a venture (Vilanova and Vitanova 2020). However, due to human's aversion to uncertainty, they adopt a cognitive mechanism (Packard et al. 2017) and take a series of actions to decrease the uncertainty that they have to undergo through the entrepreneurial process (Dimov 2007b; Wood 2017). This cognitive mechanism can be seen in entrepreneurs' propensity to analyze the market. Introduced by Emami and Klein (2020), the entrepreneurial propensity for market analysis (EPMA) drives entrepreneurs to study the market, collect relevant information, analyze it systematically, and finally take action. This recently introduced concept, EPMA, has been studied as a mediator between value creation intention and action (Emami and Klein 2020; Emami 2020); however, few researchers have studied its determinants, specifically in the time of the COVID-19 pandemic.

Individuals with innovative ideas tend to be more proactive in facing changes and take more risks than others. Risk-taking, innovativeness, and proactiveness are characteristics of people with entrepreneurial orientation (Pittino et al. 2017). Individual Entrepreneurial Orientation (IEO) assists nascent entrepreneurs to lower the level of environmental uncertainty through EPMA and induces more concrete entrepreneurial efforts (Chen et al. 2018). Therefore, the first research question deals with how the individual entrepreneurial orientation affects the EPMA.

Considering the degree to which entrepreneurs can decrease the uncertainty, they decide whether or not exploiting the opportunity makes sense (Williams and Wood 2015). On perceiving an opportunity, entrepreneurs start weighing up both the opportunity and their condition. Entrepreneurs embrace opportunities they find worth pursuing (Boudreaux et al. 2019). Provided that the perceived opportunity is deemed favorable and feasible, it can gain the entrepreneur's confidence. Moreover, having confidence in the feasibility of the idea plays a pivotal role in nascent entrepreneurs' tendency to implement the idea in a time of crisis (Davidsson 2015). Opportunity Confidence (OC) can be defined as the sufficient conviction of nascent entrepreneurs in the feasibility and operability of the perceived opportunity for sustained entrepreneurial efforts (Dimov 2010). Studies show that more OC results in a higher likelihood of entrepreneurial action (Ashourizadeh et al. 2014; Emami 
and Khajeheian 2019). Given the importance of OC in accelerating entrepreneurial actions, in this study, we investigate how the OC of nascent entrepreneurs mediates the impact of IEO on EPMA. Thus, the second research question is: How does the effect of individual entrepreneurial orientation on EPMA go through the opportunity confidence?

Additionally, entrepreneurial entry is often induced by two main motivational reasons: they are either pushed by the immediate necessity or pulled by opportunities in the market (Williams et al. 2009; Fairlie and Fossen 2020). While opportunity-based entrepreneurship is related to perceiving opportunities and taking advantage of them, necessity-based entrepreneurship is related to factors such as poverty (Amoros and Cristi 2011; Moradi et al. 2020), unemployment (Koellinger and Thurik 2012; Massar et al. 2020), and economic recession (Gonzalez-Pernia et al. 2018). These factors, all of which can be observed in the time of the COVID-19 economic crisis, force people to start a business to compensate for the financial pressure caused by the lack of resources (Shane 2003; Valdez and Richardson 2013; Ferraris et al. 2020). However, another side of the COVID-19 pandemic brings about changes and, therefore, opportunities. So, in this study, we are interested in exploring approaches and individuals' motives for entrepreneurship, which help us realize and appreciate the silver lining of this crisis. As such, the third question we ask is: how do the entrepreneurial motives, i.e., opportunity-driven and necessity-driven entrepreneurs, may moderate the direct and mediating effects on EPMA. It is of crucial importance to demonstrate these effects since these can provide us with better insight into entrepreneurs' decision-making process and what drives them to analyze the condition of the market and the possible imposed changes, specifically in the time of the COVID-19 crisis.

Nonetheless, for the purpose of this study and to explain the fundamental concepts of our proposed model, we apply the theory of reasoned action (Fishbein and Ajzen 1975). This theory fits with our study since it is an explanation of why and how action happens. To quantitatively fulfill the research objective, we use a questionnaire to gather data from a sample of 203 nascent entrepreneurs within the timeframe of the COVID-19 pandemic.

This study contributes to the application and expansion of the theory of reasoned action, particularly in a crisis. We identify the determinants of an intention (EPMA) that lead to an action, i.e., entrepreneurial action. Additionally, we find out that the impact of IEO upon EPMA goes through OC. This mechanism highlights the uniqueness of this study. We not only explored the relationships and mechanisms among our concepts, but we have also scrutinized the model from the micro and macro level. From the micro-level, we demonstrated the impact of the entrepreneur's motive on entrepreneurial activity in the proposed model, and from the macro-level, we highlighted the influence of COVID-19 on our hypothesized model.

\section{Theory and hypothesis development}

This section first reviews the Theory of Reasoned Action (TRA) and describes how it explains our research model. We then go forward and propose related hypotheses. 
TRA is concerned with individual motivational factors that predict the likelihood of performing a specific behavior. Fishbein and Ajzen (1975) assume a causal chain effect from attitudes to voluntary actions and behaviors with and without any force. They demonstrated that attitudes toward an intention that leads to action are better predictors than attitudes toward an object. For example, according to Fishbein and Ajzen (1975), in entrepreneurial action, we are recommended to concentrate on behaviors towards entrepreneurial action rather than the action per se. Attitudes come from individuals' beliefs about the consequences of performing a behavior. When a person believes in positive outcomes of a behavior, it is said that he has a strong attitude toward that behavior which consequently leads to the action (Ajzen and Fishbein 1980; 2005). A fundamental assumption in TRA is that individuals are rational actors. Via their beliefs, they provide reasons, process information, and perform a behavior (Fishbein et al. 2007). It is also assumed that it is a person's choice that leads to behavior without external forces and that individual action is not deterministic but actors have a degree of control over it.

Since we believe that entrepreneurial action is under volitional control, we consider that EPMA is a suitable predicting behavior for this action. The EPMA is a driving force behind entrepreneurs to undertake an entrepreneurial action; they study the market, collect relevant information, and analyze it systematically prior to entrepreneurial venturing (Emami and Klein 2020). The theory of reasoned behaviour helps us in explaining the motivational determinants of this behavior and in formulating the hypotheses.

\subsection{The entrepreneurial propensity for market analysis}

Alert nascent entrepreneurs search for new information, scan and integrate it with previously distant information, and then evaluate the profitability of existing business opportunities (Tang et al. 2012). Individuals with entrepreneurial alertness can make informed judgments and evaluations by concentrating on changes and information and deciding if they reflect a profitable opportunity (Tang et al. 2012).

When entrepreneurs evaluate an opportunity, they have a fundamentally different thought process (Keh et al. 2002). Forming opportunity ideas is related to entrepreneurs' previous experiences, changes in the market's environment, and acquiring information (Shane 2000; Gaglio and Katz 2001; Shepherd et al. 2007a, b). Nevertheless, not all opportunities noticed are exploited by entrepreneurs since, after comprehensive entrepreneurial analyses, entrepreneurs might conclude that the perceived opportunity is not feasible or favorable. As a result, they could lose their confidence in the perceived opportunity.

Individuals deciding to invest in or establish a company need a wealth of information that must be processed and analyzed swiftly to decide about possible involvement (Baum and Wally 2003; Sharma 2019). However, entrepreneurs have a different attitude toward exposing themselves to information; they seek various information sources and evaluate information differently (Kaish and Gilad 1991; Chavoushi et al. 2020). While analyzing the market, entrepreneurs tend to seek 
information that corroborates their current beliefs and intentions about the opportunity (Dimov 2007a; Glick 2017).

The entrepreneurial propensity for market analysis (EPMA) is a conscious tendency to acquire new information to validate or rule out early assumptions. EPMA is a driving force behind entrepreneurs studying the market, collecting relevant information, and systematically analyzing it prior to entrepreneurial venturing (Emami and Klein 2020). EPMA has an important role in determining whether to perform an entrepreneurial action by motivating individual to obtain the market's idiosyncratic knowledge. In re-evaluating ideas and possible income, nascent entrepreneurs gain access to previously unavailable information (Dimov 2010). Analyzing this information can lead to hesitation about the opportunity and allows them to decide whether to continue or abandon their endeavor to pursue perceived opportunity (Dimov 2010).

\subsection{EPMA depends on individual entrepreneurial orientation}

IEO is defined as decision-making activities, practices, and processes undertaken by entrepreneurs to facilitate new entry (Lumpkin and Dess 1996). Although EO was initially developed on the firm level, the construct is also proved to be pertinent to the societal level (Lee and Peterson, 2000; Cannavale and Nadali 2018). In that, the majority of small entrepreneurial firms are operated by only one decision-maker. Therefore, it can be concluded that a firm's EO is coequal to individual decisionmakers EO (Kollman et al. 2007; Kruger and Sussan 2017) and entrepreneurial opportunities are discovered and decisions are made subjectively at the individual level (Packard 2017; Shane 2003). Accordingly, EO can likewise be applied to the individual level (Kollman et al. 2007). IEO is a multidimensional construct that involves proactiveness, risk-taking, and innovativeness (Joardar and Wu 2011; Ferreira et al. 2015; Jelenc et al. 2015; Howard M.C. 2020).

The propensity for doing systematic market analysis differs among entrepreneurs (Emami and Klein 2020). Also, the determinants of IEO are specific to each individual (Kollman et al. 2017). The perception of the feasibility of an opportunity is specific to each individual depending primarily on their knowledge and attitude about uncertainty and their efforts to explore the viability of the particular opportunity (McMullen and shepherd 2006; Dimov 2010; Gruger et al. 2015).

Entrepreneurs have an appetite for logical calculations and planning (Martiz et al. 2020; Dew et al. 2009). A recent study on Australian entrepreneurs demonstrates that developing clear plans and specific tasks are the key for entrepreneurs to increase their action certainty (Martiz et al. 2020). Indeed, studies suggest that entrepreneurs are not mere risk-takers, but they tend to analyze how much they can afford to take a risk on or lose (affordable loss) and they look for solutions to manage risk in environmental uncertainty (Dew et al. 2009). This proclivity for calculated risk (Nieuwenhuizen and Groenewald 2006) drives them to perpetually analyze the market (Zhao and Smallbone 2019). On the one hand, innovativeness shows entrepreneurs' tendency to try new methods and state-of-the-art facilities and products. On the other hand, it requires doing painstaking ongoing research in the 
ever-changing market. As a result, entrepreneurs need to perform a detailed analysis of the most recent changes. This analysis can give entrepreneurs a chance to address the new needs innovatively and keep pace with the most cutting-edge technologies. Entrepreneurs' proactiveness is the extent to which entrepreneurs are willing to consciously affect their social and economic environment (Bateman and Crant 1993). Proactiveness prevents entrepreneurs from being mere passive recipients and instead provokes co-creating their work environment (Zhao and Smallbone 2019). Proactive entrepreneurs are willing to be in control rather than under the control of the market, which makes them more prone to seek in-depth knowledge of the market (Zhao and Smallbone 2019).

The COVID-19 pandemic can be considered as an external enabler of IEO`s dimensions. Due to uncertainty caused by the pandemic, risk-taking behavior will increase. So, nascent entrepreneurs need to collect information and analyze the market to decide whether this opportunity is feasible or not. Also, because of the COVID-19 pandemic and new situation and new norms, new methods are applied and entrepreneurs need to study the market to find new methods and products. Finally, the COVID-19 pandemic influences the proactive aspect of IEO. As a result, entrepreneurs will analyze the situation and various information to be pioneers and influence the environment and conditions. Thus, we hypothesize that:

Hypothesis $\mathbf{H 1}$ In the time of the pandemic, individual entrepreneurial orientation affects EPMA positively, in that the higher the individual entrepreneurial orientation, the higher the EPMA.

\subsection{The mediating role of opportunity confidence}

To continue the entrepreneurial journey, a nascent entrepreneur needs to have sufficient confidence in the feasibility and desirability of the perceived opportunity, which is called OC (Dimov 2010). According to TRA, when a person believes in positive outcomes of a behavior, that will lead to action (Ajzen and Fishbein 1980; Ajzen 1991). Nascent entrepreneurs need to believe in the feasibility of the idea and their ability to exploit the perceived opportunity (Dimov 2010). In assessing the feasibility of a given opportunity, entrepreneurial self-efficacy is venture-specific and related to an entrepreneur's goal and motivation (Cassar and Friedman 2009; Dimov and Pistrui 2020).

To examine the feasibility, nascent entrepreneurs, in their decision-making process, look at the opportunity from both a third-person perspective (to see whether it is a commonsensible opportunity in general) and from the first-person perspective (to check if it is desirable for them) (McMullen and Shepherd 2006). Looking at the opportunity from the first-person view, nascent entrepreneurs have to evaluate their assets and consider their traits as well. A thorough appraisal of the perceived opportunity can help them decide whether the requirements of this opportunity can be met by their assets at hand. Individual and environmental factors amalgamate to form the attractiveness of the opportunities and help entrepreneurs individuate them (Williams and Wood 2015). 
This assessment is specific to individuals in that no two entrepreneurs have identical self-assessment, even if they are given the very same assets to start a business. In this circumstance, what differentiates entrepreneurs is their opportunity beliefs (Shepherd et al. 2007a, b). Entrepreneurs show different levels of tendency toward risks. They are not likewise equally proactive or innovative. Proactiveness is a forward-looking perspective of entrepreneurs that enables them to grab opportunities and anticipate future demands (Dess and Lumpkin 2005). More proactive individuals notice and grab opportunities faster, and individuals' innovativeness can help them contrive more plausible ingenious ways to implement the idea. They all result in more confidence in the perceived opportunity. Innovativeness and risk-taking induce a higher sense of self-efficacy (Chen et al. 1998; McCann and Vroom 2015). In uncertain situations, entrepreneurs' estimations significantly depend on individuals' belief in their abilities and self-efficacy (Macko and Tyszka 2009).

Since OC is deeply dependent on the environment, COVID-19 may dramatically affect confidence in an opportunity and daunt an entrepreneur. However, having IEO in the pandemic may change the game, and the entrepreneur may gain higher confidence due to the higher innovativeness, risk-taking, and proactiveness that they gain in the pandemic. So, we surmise that:

Hypothesis $\mathrm{H} 2$ In the time of the pandemic, individual entrepreneurial orientation has a positive influence on opportunity confidence, in that the higher the individual entrepreneurial orientation, the higher the opportunity confidence.

In their evaluation of competency (i.e., knowledge and expertise), resources (both financial and non-financial), the desirability of opportunity idea (Davidsson 2015; Mitchell and Shepherd 2010), and futuristic outcomes (Camerer and Lovallo 1999; Hayward et al. 2006; Cassar 2010), nascent entrepreneurs may discontinue their progress (Emami and Klein 2020). Several factors decrease OC; for instance, entrepreneurs come to the realization that they have set unrealistic and unattainable goals due to deceptively high self-efficacy and underestimating the environmental uncertainty (Vilanova and Vitanova 2020). They may also find out that their tolerance of ambiguity cannot support the gaps.

However, the higher their $\mathrm{OC}$ is, the more likely they are to continue analyzing the market and therefore go for entrepreneurial action. If they lose their confidence in the possibility of exploiting an opportunity, they will not feel the necessity to continue the course of action. Attitudes towards consequences of performing a behavior, increase the confidence in that behavior (Fishbein and Ajzen 1975; Ajzen and Fishbein 1980; Ajzen 1991). Here in our case, higher confidence in an opportunity comes from attitudes toward that opportunity and its consequences, both of which lead to higher EPMA.

COVID-19 has raised to uncertainties and ambiguities that need to be analyzed. Entrepreneurs with higher confidence that an opportunity is desirable and feasible may have a higher propensity to analyze the market. Thus, we hypothesize that: 
Hypothesis $\mathbf{H} 3$ In the time of the pandemic, opportunity confidence has a positive influence on EPMA, in that the higher the opportunity confidence, the higher the EPMA

\subsection{The moderating role of opportunity-pull and necessity-push entrepreneurship}

To understand nascent entrepreneurs' motives for starting an entrepreneurial journey, scholars distinguish between individuals driven (pulled) by perceived opportunity and those driven (pushed) by necessity (William et al. 2009; Moradi et al. 2020). Motivations such as the need for a sense of achievement and independence as well as social development pull entrepreneurs to opportunity entrepreneurship. In contrast, necessity entrepreneurship is rooted in dissatisfaction with the current condition or the likelihood of unemployment (Zwan et al. 2016) and is implemented out of desperation (Mühlböck et al. 2018). In other words, these two types of entries are stimulated in different ways (Elifneh 2015). Opportunity entrepreneurship is rooted in cheaper or more available capital, high entrepreneurial ability, discovering a better production method, and higher demand for products or services in the market (Fairlie and Fossen 2018).

Zwan et al. (2016) found that more optimistic and proactive people tend to be opportunity entrepreneurs. Therefore, it can be concluded that entrepreneurship entry mode is related not only to economic conditions but also to individuals' perspectives and perceptions. When entrepreneurs with an opportunity-driven approach decide to exploit the opportunities, they have the willingness to risk and take advantage of them. In practice, they apply innovative practices and processes to exploit the perceived opportunity. At the individual level, studies show that entrepreneurs' motivation to start a business can affect how they see barriers (Shane et al. 2003), how they perceive opportunities (Abreu et al. 2019; Virick et al. 2015), how they obtain market knowledge (Autio et al. 2013; Arenius \& Minniti 2005), and to what extent they feel confident about their self-efficacy and business goal (Bagozzi et al. 2003; Heckhausen 2007). Individuals with opportunity-driven motives try to proactively remove barriers through innovative actions and are willing to take risks to pursue the opportunity. In comparison with necessity entrepreneurs, opportunity entrepreneurs tend to be individuals with a higher level of risk acceptance, an internal locus of control, and a stronger need for achievement (Shane et al. 2003).

It is specifically more evident in the pandemic, since opportunity entrepreneurs see the new situation and uncertainties as an opportunity to be exploited. So, such a motive may transcend the impact of IEO on EPMA and OC. Also, entrepreneurs with opportunity motives in the pandemic will gain higher confidence towards opportunities and, thus, will have a higher tendency to analyze the market. Therefore, we surmise that, in the time of pandemic, entry mode into entrepreneurship moderates our relationships as follows: 
Hypothesis H4a Entrepreneurial entry mode (opportunity vs. necessity) moderates the effect of individual entrepreneurial orientation upon EPMA in the time of the pandemic.

Hypothesis H4b Entrepreneurial entry mode moderates the effect of individual entrepreneurial orientation upon opportunity confidence in the time of the pandemic.

Hypothesis H4c Entrepreneurial entry mode moderates the effect of opportunity confidence upon EPMA in the time of the pandemic.

Figure 1 illustrates the research model of the hypotheses mentioned above. The direct effect of IEO on EPMA and how OC mediates it has been shown and the moderating effect of entrepreneurial entry mode (opportunity vs. necessity) on the relationships of IEO, OC, and EPMA.

\section{Methodology}

The purpose of this study is to examine the mediating role of OC in the relation between IEO and EPMA and the moderating role of entrepreneurship entry mode. As such, we employed a descriptive-correlation method and used a questionnaire consisting of twenty items, distributed and responded to in the time of the COVID19 pandemic in 2020. The sample of the study comprised 203 nascent entrepreneurs in the field of ICT in Science and Technology and Innovation Centers in Iran. Nascent entrepreneurs are individuals in the process of creating a new venture in the conception or gestation phase (Reynolds et al. 2000).

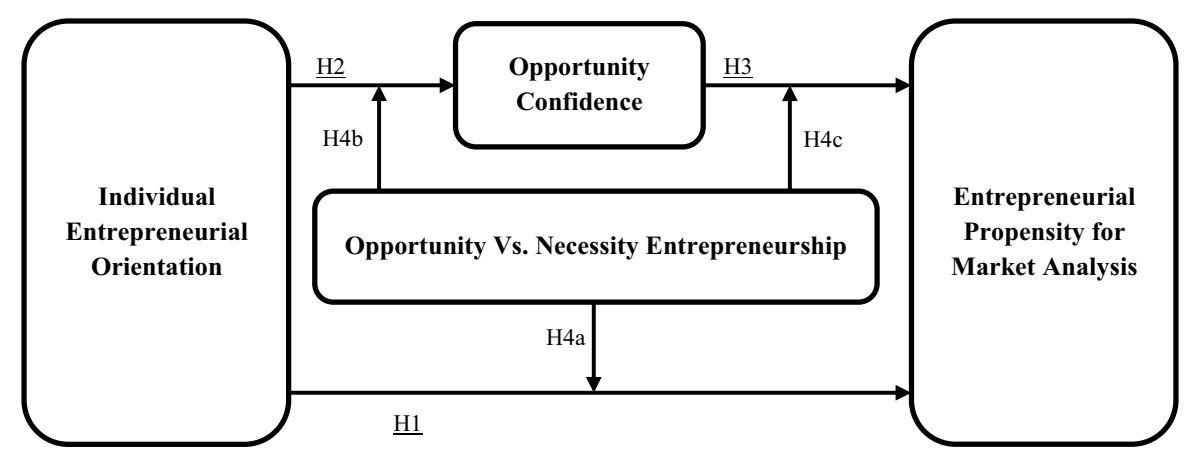

Fig. 1 The hypothesized model of the study 


\section{Research context}

The geographical research context of this paper is Iran. Iran is one of the notable economies of the Middle East that is geopolitically distinct from the rest of the countries in the region due to several factors. The geographical location of Iran gives it the privilege to play a pivotal role in world energy supplies and exchanges. Besides having many tourist attractions and a thriving tourism industry, the country enjoys rich natural resources and highly well-educated human resources. Notwithstanding all these advantages, Iran is located in a war-ridden region with pervasive political conflicts and is frequently struck by natural disasters (Javidan and Dastmalchian 2003).

From a cultural standpoint, a high level of power distance has a dramatic effect on entrepreneurship. It can daunt people of lower social class due to not having access to necessary resources (Mitchell et al. 2000). On the contrary, in other studies in countries with low or middle GDP, a positive relationship between social power distance and entrepreneurship is observed (Zhao et al. 2012). Thus, Iran, with low GDP and a high level of power distance, has a prevalence of entrepreneurship.

Collectivism is another aspect of Iranian culture that can affect entrepreneurial behavior. Iranian culture promotes loyalty to family and friends (in-group collectivism). The higher the level of in-group collectivism, the higher likelihood of starting business activities (Pinillos and Reyes 2011; Zhao et al. 2012). In the time of a crisis, such in-group connections provide them with necessary resources (such as emotional support or information support) to pursue entrepreneurial activities (as we observed a higher percentage of opportunity entrepreneurs in comparison to necessity entrepreneurs in our sample). Given the culture, the context of Iran has both deterrents and impetuses for entrepreneurs. While high power distance may hinder the equal distribution of resources for individuals' business activities, in-group cohesion may support them to start an entrepreneurial activity.

However, business activities within the entrepreneurial ecosystem in Iran involve a high degree of environmental volatility, ambiguity, and complexity, making it difficult for domestic entrepreneurs to perform required maneuvers. Following the outbreak of the Coronavirus, both inner and outer causes have made business activities even more intricate for Iranian entrepreneurs. Some of the potential causes are:

(i) A high degree of regulatory uncertainty makes business planning difficult and hampers early-stage investment (Emami and Klein 2020).

(ii) The country's political atmosphere impacts commerce as well as daily life and poses challenges in doing business within and across national boundaries (Emami and Khajeheian 2019).

(iii) The government intervenes in regulating the market and the imposed economic sanctions have suspended almost all interbank transactions for businesses abroad (Emami and Klein 2020).

(iv) The inefficiency of the nuclear deal of Joint Comprehensive Plan of Action between Iran and the world powers has increased libertine inflation, budget defi- 
cit, and a simultaneous decline in supply and demand in the economy, increasing the price of foreign currencies, and

(v) Shifting the budget to the health sector at the cost of reducing the share of other construction and investment sectors has led to an economic recession and a major drop in the GDP level (Taherinia and Hasanvand 2020). For instance, the country's economy has shrunk by 17 percent in the last three years only because of sanctions.

The country's employed population in the fall of 2020 compared to the same season the earlier year decreased by one million, $72 \%$ of which belonged to the service sector. According to the Parliament Research Center of Iran, the prevalence of the COVID-19 is the reason for the sharp plummet in the unemployment rate that hit $18.4 \%$ in the fall (IPRCIRI 2020). All of these factors have had an immense negative impact on the activities of nascent entrepreneurs regarding both necessity- and opportunity-driven entrepreneurs in the country.

We believe that the concurrency of the Corona pandemic and the cultural, geographical, and economic conditions of Iran (some of which have been reviewed above) have given a particular context that should be considered in the study of entrepreneurial behavior.

This study focuses on four important factors in entrepreneurship research: IEO, OC, EPMA, and motivation entry to entrepreneurship. The study of these factors is instrumental in the process of new venture creation in this volatile, uncertain, risky, and complex environment. Especially because the population distribution of opportunity and necessity-driven entrepreneurs, as two main modes of entrepreneurial entry, are relatively equal (GEM 2018; 2019) and for analyzing the idiosyncratic information of the market, EPMA is a driving factor. Besides, entrepreneurs with a higher level of IEO have better performance (Galbreath et al. 2020) and individuals with a higher level of OC are closer to venturing (Dimov 2010).

\subsection{Measurement}

\subsubsection{Dependent variable}

Entrepreneurial Propensity for Market Analyses (EPMA). EPMA is comprised of six items adapted from Emami and Klein (2020). Items were gauged on a fivepoint Likert scale ranging from $1=$ strongly disagree to $5=$ strongly agree. The level of reliability and for EPMA is 0.64, which according to Hulin et al. (2001), is an acceptable level. In order to build a stronger variable, EPMA items were indexed.

\subsubsection{Independent variable}

Individual Entrepreneurial Orientation (IEO). IEO has been measured based on Walter (2006). The construct consists of risk-taking, innovation, and proactiveness in the form of five items. The items were assessed based on a five-point Likert 
Table 1 Descriptive Analyses

\begin{tabular}{llll}
\hline Gender & Percentage & Age & Percentage \\
\hline Male & $66 \%$ & $<25$ & $29.3 \%$ \\
Female & $34 \%$ & $26-35$ & $44.3 \%$ \\
& & $36-45$ & $20.9 \%$ \\
& & $>45$ & $5.5 \%$ \\
Total & $100 \%$ & Total & $100 \%$ \\
Entry mode & & Experience & \\
Necessity & $21.7 \%$ & $<10$ yrs & $73.9 \%$ \\
Opportunity & $78.3 \%$ & $10-20$ yrs & $22.7 \%$ \\
& & 20 yrs $<$ & $3.4 \%$ \\
Total & $100 \%$ & Total & $100 \%$ \\
\hline
\end{tabular}

Total number of cases: 203

Table 2 The correlation of the variables

\begin{tabular}{llllll}
\hline Variable & Mean & Standard dev & OC & IEO & EPMA \\
\hline OC & 5.1931 & 1.365 & 1 & & \\
IEO & 5.1248 & 0.967 & $0.309 * *$ & 1 & \\
EPMA & 5.6478 & 0.792 & $0.541^{* *}$ & $0.285^{* *}$ & 1 \\
\hline
\end{tabular}

**. Correlation is significant at the 0.01 level (2-tailed)

scale ranging from $1=$ strongly disagree to $5=$ strongly agree. The Cronbach Alpha $(=0.88)$ shows high reliability of the items; therefore, the items were indexed by taking the average.

(OC). We measured this concept according to Dimov's (2010) and Emami and Dimov's (2017) studies. It includes nine items in a five-point Likert scale ranging from $1=$ strongly disagree to $5=$ strongly agree. The reliability of the items is Cronbach Alpha $=0.8$ which demonstrates that the items are highly reliable.

\subsubsection{Moderating variable}

Entrepreneurship Entry Mode (Opportunity vs. Necessity). This dichotomous variable has been measured based on GEM's questionnaire.

\subsection{Research method}

To test the hypotheses, we analyze our data through One-way ANOVA and Linear Regression. 
Table 3 Model Summary

\begin{tabular}{lllll}
\hline Model & R & R Square & $\begin{array}{l}\text { Adjusted R } \\
\text { square }\end{array}$ & $\begin{array}{l}\text { Std. error of } \\
\text { the estimate }\end{array}$ \\
\hline 1 & $.285^{\mathrm{a}}$ & .081 & .077 & .76105 \\
2 & $.555^{\mathrm{b}}$ & .308 & .301 & .66238 \\
\hline
\end{tabular}

a. Predictors: (Constant), IEO

b. Predictors: (Constant), IEO, OC

Table 4 Coefficient of Variables

\begin{tabular}{lllll}
\hline & Model 1 & Model 2 & Model 3\# & Model 4 \\
\hline IEO & $.166 * * *$ & & $.219 * * *$ & $.076 *$ \\
OC & & $.443 * * *$ & & $.410 * * *$ \\
Constant & $4.788^{* * *}$ & $3.379 * * *$ & $3.988 * * *$ & $3.154 * * *$ \\
\hline
\end{tabular}

\# DV is OC

$* p<.05 * * p<.01 * * * p<.001$

\section{Result}

\subsection{Descriptive statistics}

Table 1 shows that the majority of the respondents (about 74\%) have less than ten years of experience. Approximately one-fifth of them have 10 to 20 years of experience and only $3 \%$ of the respondents have more than 20 years of experience.

Similarly, the majority of the respondents (about 77\%) are less than 35 years old, $21 \%$ are 36 to 45 years old and merely 11 percent are 45 years or older.

Male entrepreneurs make up approximately twice as many as female entrepreneurs (66\% vs. $34 \%)$.

Interestingly in the time of the COVID-19 pandemic, $78 \%$ of the respondents fall into opportunity-based entrepreneurship and $22 \%$ are necessity-based entrepreneurs.

Table 2 presents the strength of the relationship and the association between the pair of variables. The result indicates that all pairs of variables are significantly correlated. EPMA and OC recorded the strongest positive correlation $(r=0.541)$, followed by IEO and OC $(r=0.309)$, which is considered a medium or moderate positive correlation. Finally, EPMA and IEO with $r=0.285$ showed the least association coefficient. Since all correlation coefficients were positive and statistically significant, we tested the Variance Inflation Factor (VIF) and found no potential multicollinearity among independent variables (Stine 1995). Additionally, we found no abnormal distribution among variables, and all fall within the acceptable range of Skewness and Kurtosis. 


\subsection{The mediating role of $\mathrm{OC}$}

Table 3 Model 1 is the relationship between IEO and EPMA without considering OC. Here, R-square equals 0.081, and with the presence of OC (Model 2), R-square increases by 0.227 and reaches 0.308 . It shows the meaningful and significant role of $\mathrm{OC}$ in changing and describing the dependent variable (EPMA).

Table 4 presents four models for testing the mediating relationship through testing the hypotheses $\mathrm{H} 1, \mathrm{H} 2$, and $\mathrm{H} 3$.

Hypothesis $\mathrm{H} 1$ has predicted the positive effect of IEO upon EPMA. The result (Model 1) confirms the positive and highly significant impact of IEO upon EPMA $(\beta=0.166, P$-value $<0.001)$. In that, the higher IEO the higher EPMA. Thus, hypothesis $\mathrm{H} 1$ is supported.

Hypothesis $\mathrm{H} 2$ is about the impact of IEO upon OC. The result from Linear Regression (Model 3) demonstrates that IEO has a positive and significant effect on OC $(\beta=0.219, P$-value $<0.001)$. It means that higher IEO results in higher OC. Therefore, hypothesis $\mathrm{H} 2$ is supported.

Hypothesis $\mathrm{H} 3$ assumes that OC influences EPMA. The result from analysis (Model 2) exhibits that there is a positive and significant impact of OC on EPMA, in the way that the higher the OC, the higher the EPMA $(\beta=0.443, P$-value $<0.001)$. Hence, hypothesis H3 is supported.

To understand the mediating role of the OC between IEO and EPMA, we further analyzed the impact of OC on EPMA while the independent variable IEO is fixed. The result indicates that both OC and IEO have a positive and significant effect on EPMA.

Therefore, in respect of the above analyses (Models 1, 2, 3, and 4), we conclude that there is a mediating role of OC between IEO and EPMA.

\subsection{The moderating role of motivation entry to entrepreneurship}

Table 5 presents the results from interactions. Hypothesis $4 \mathrm{a}$ is about the interaction effect of motivation entry into entrepreneurship and IEO upon EPMA.

Table 5 The Coefficient of variables

\begin{tabular}{llllll}
\hline $\begin{array}{l}\text { Entrepreneurship } \\
\text { Entry Mode }\end{array}$ & Variables & Model 5 & Model 6 & Model 7\# & Model 8 \\
\hline Necessity & IEO & .138 & & .164 & .113 \\
& OC & & $.182^{*}$ & & .148 \\
& Constant & $4.956^{* * *}$ & $4.803^{* * *}$ & $3.693^{* * *}$ & $4.410^{* * *}$ \\
Opportunity & IEO & $.175^{* * *}$ & & $.195^{* * *}$ & .064 \\
& OC & & $.597 * * *$ & & $.568^{* * *}$ \\
& Constant & $4.730^{* * * *}$ & $2.491^{* * *}$ & $4.271^{* * *}$ & $2.306^{* * *}$ \\
\hline
\end{tabular}

\# DV is OC

$* p<.05 * * p<.01 * * * p<.001$ 


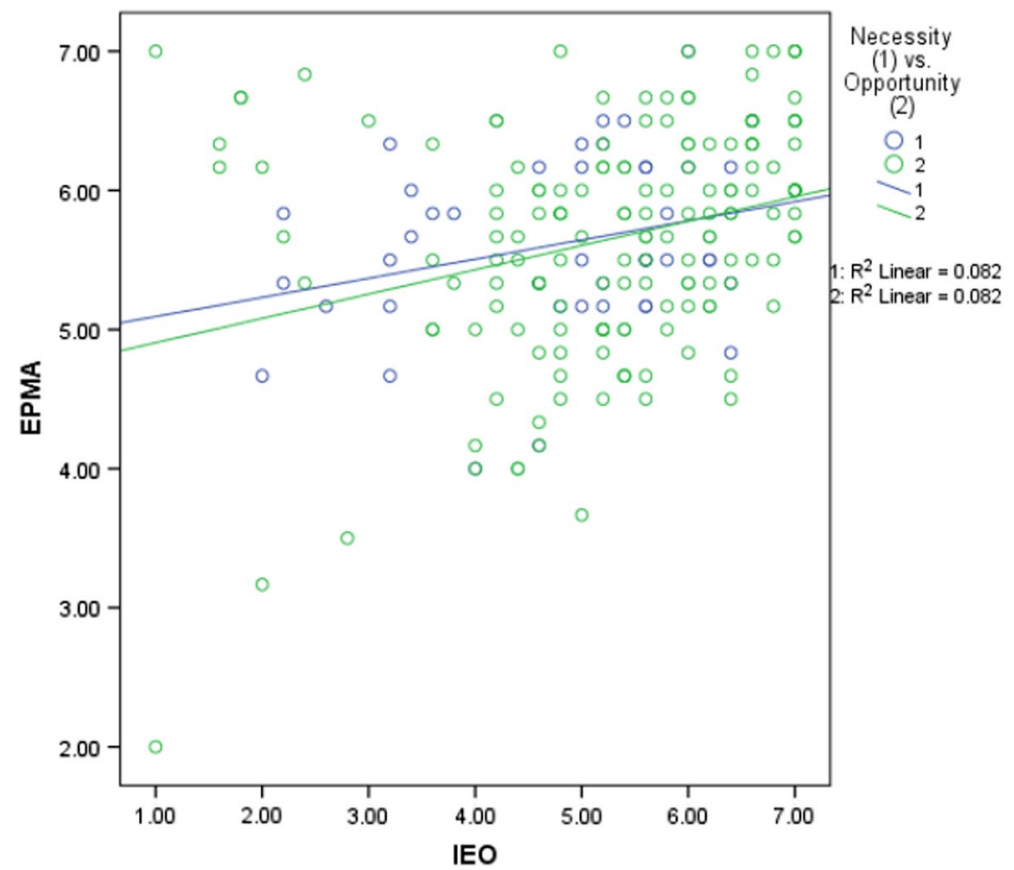

Fig. 2 Interaction effect of IEO and entrepreneurial entry mode on EPMA

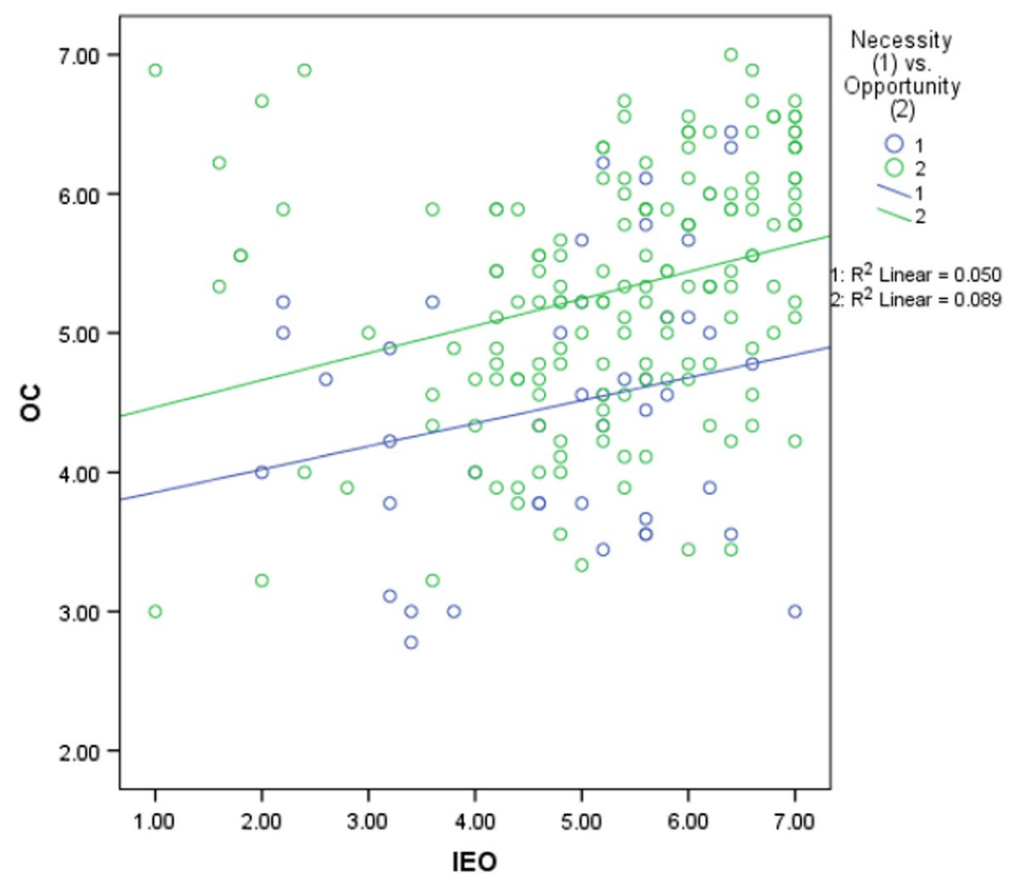

Fig. 3 Interaction effect of IEO and entrepreneurial entry mode on OC 


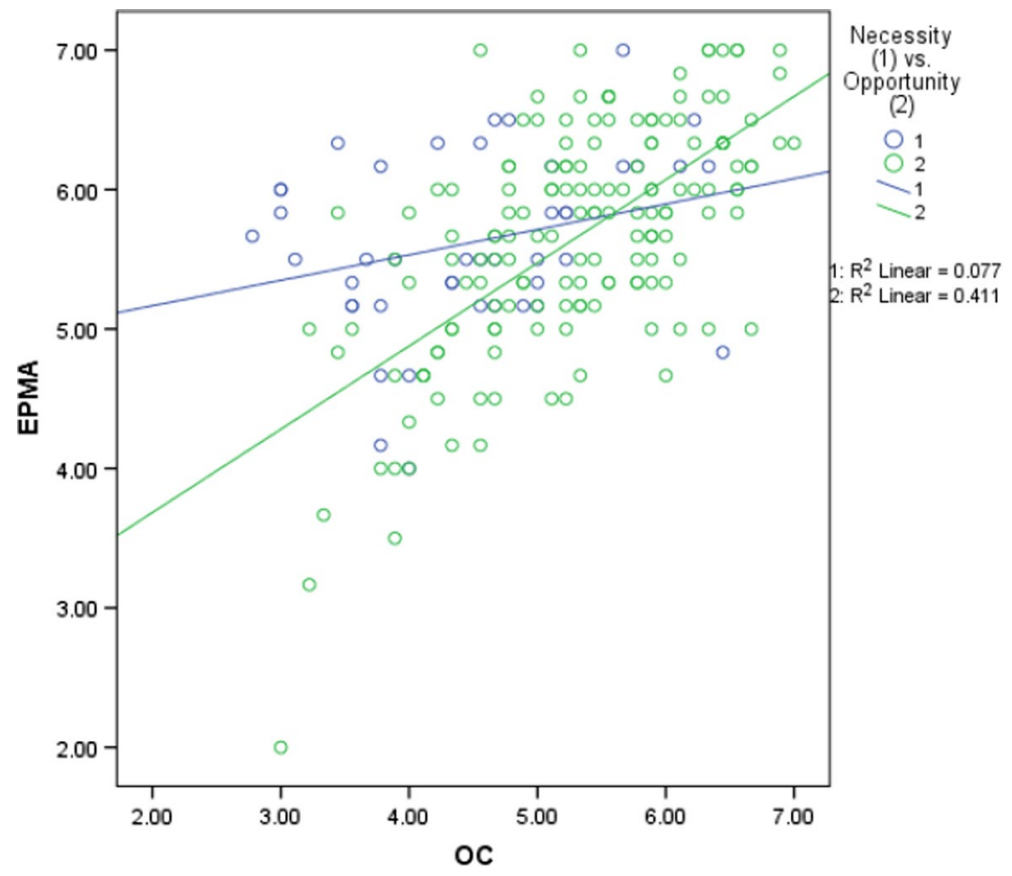

Fig. 4 Interaction effect of OC on EPMA

Results in Model 5 show the significant impact of IEO on EPMA only for opportunity entrepreneurs and not for necessity entrepreneurs. Therefore, hypothesis $4 \mathrm{a}$ is not supported. Figure 2 depicts the insignificant interaction between IEO and entrepreneurial entry mode with EPMA in this model.

Hypothesis $4 \mathrm{~b}$ assumes that the entrepreneurial entry mode moderates the impact of IEO on OC. Analyses in Table 5, model 7, exhibit that the interaction between IEO and entrepreneurial entry mode is only significant for opportunity entrepreneurs and not for necessity entrepreneurs. Thus, hypothesis $4 \mathrm{~b}$ is not supported. Figure 3 depicts that the interaction of IEO and entrepreneurial entry mode on OC is not significant.

Hypothesis $4 \mathrm{c}$ proposes that the interaction effect of entrepreneurial entry mode and OC affects EPMA. Results in Table 5, model 6, demonstrate that there is a significant interaction; in the way that the impact of OC on EPMA is higher among opportunity entrepreneurs than necessity entrepreneurs. Therefore, hypothesis $4 \mathrm{c}$ is supported. Figure 4 depicts that the impact of OC on EPMA is higher among opportunity-driven entrepreneurs than necessity-driven entrepreneurs.

Considering all analyses, we conclude that there is no moderation-mediation effect in the model. Nonetheless, it brings intriguing insights that will be discussed in the next section. 


\section{Discussion}

The emergence of a venture results from a complicated decision-making process in which different success factors such as the readiness of the entrepreneur, the environmental condition, and the evaluation of new venture ideas play an important role (Mcmullen and Shepherd 2006). The findings of this study elucidate how nascent entrepreneurs are driven through this decision-making process during the pandemic and specify determinants of entrepreneurs' tendency toward evaluations of the market. According to the results, nascent entrepreneurs with higher IEO have more confidence in the perceived opportunity, and they show a higher propensity to do a market analysis and evaluate the environment. Additionally, the more confidence they have in the immediate opportunity, the more tendency they show to analyze the market. The analyses validated the mediating role of OC in the relation of IEO and entrepreneurial propensity for market analysis. That is, while OC is dependent on IEO, it can affect EPMA.

Our study suggests that IEO has a positive effect on OC and EPMA. Three dimensions of IEO — risk-taking, proactiveness, and innovation- influence entrepreneurs' confidence in the opportunity positively. Facing a high level of uncertainty can dismay entrepreneurs and result in losing confidence in the opportunity. Nevertheless, risk-taking tendency and proactiveness push entrepreneurs forward in their entrepreneurial journey and help entrepreneurs keep their faith in their capability to exploit the given opportunity and make them deem the opportunity feasible. Innovativeness, on the other hand, helps entrepreneurs devise ways how to use the perceived opportunity. Higher innovativeness results in finding more creative ways to implement the idea. And as a result, innovativeness makes entrepreneurs confide in the feasibility of the opportunity.

Additionally, results from analyses show that IEO`s dimensions positively affect EPMA. While entrepreneurs are willing to take risks, they collect information and analyze it to find out how much they can take a risk. Thus, we believe that the higher willingness for risk-taking results in higher EPMA. IEO`s proactiveness dimension results in higher EPMA. Typically, proactive entrepreneurs take action to exploit an opportunity; however, they do not take action without collecting relevant information, analyzing it systematically. So, the higher degree of proactiveness among entrepreneurs leads to higher EPMA. Innovativeness is a tendency to try new methods and introduce new products, which requires searching for new information and seeking to have the latest knowledge about changes in the market. Nonetheless, entrepreneurs with a higher degree of innovativeness have a higher tendency for EPMA since it helps them find a new market and apply innovative production methods.

Given the result of the analysis, entrepreneurial entry mode did not moderate most of the relationships of the model except for the impact of the OC on EPMA. Higher IEO leads to higher confidence in the perceived opportunity (OC) and also results in a higher propensity to analyze the market (EPMA) irrespective of whether entrepreneurship is necessity-driven or opportunity-driven. However, it positively moderated the impact of OC on EPMA in the way that 
opportunity entrepreneurs experience the higher impact of OC on EPMA. That is, in opportunity entrepreneurship, the relation between IEO and EPMA is considerably more significant. Opportunity entrepreneurs gain higher confidence in the perceived opportunity; therefore, they have a higher tendency to analyze the market regarding that opportunity. It is a novel finding not only for entrepreneurship necessity-opportunity literature but also for our understanding of nascent entrepreneurs' endeavors in a time of a crisis.

It is generally believed that entrepreneurship increases in times of an economic crisis and recession (Fairlie and Fossen 2020). In this time, for nascent entrepreneurs, necessity motives (push factors) are expected to increase (Arrighetti et al., 2016); however, the findings of our study indicate a different result. Although this study was carried out during the COVID-19 pandemic crisis, most entrepreneurs $(78.3 \%)$ were pulled by an opportunity perceived in the time of the crisis, which is in contrast with the commonly held view (Zissimopoulos and Karoly 2010). A study conducted by Mair et al. (2007) showed that opportunities emerge in the absence of institutional arrangements in developing countries. Entrepreneurs use this institutional void caused by ineffective governance, information asymmetries, and weak disclosure requirements to exploit the opportunities made in this environment. Their finding can justify the prevalence of opportunity entrepreneurship in Iran as a developing country at the time of the pandemic. There are opportunities around a crisis. Therefore, entrepreneurship is the unsung hero during this economic crisis.

\subsection{The research framework in the time of the COVID-19 pandemic}

Due to the COVID-19 crisis, the market is not only more volatile but also more unpredictable than ever before. Uncertainty has skyrocketed and the market has collapsed. This condition can daunt entrepreneurs and dishearten the ones who lack information and confidence in the perceived opportunity. In order to assess either the success or the possible impending losses, entrepreneurs tend to do a more rigorous analysis of this uncertain market.

They speculate upon the inevitable short and long-term consequences of these changes. Entrepreneurs' OC is deeply rooted in attitudes that are critically dependent on the environment. Every slight change in the market can lead to considerable change in the feasibility and favorability of the opportunity at hand. To ensure that the investment still makes economic sense, entrepreneurs need to obtain sufficient reliable information.

Depending on the obtainable information, uncertainty can be mild, severe, or absolute. While mild uncertainty has a negligible impact on entrepreneurs' decisions, severe uncertainty -like what is being experienced during the COVID-19 crisis- might make entrepreneurs unable to differentiate relevant from irrelevant information in the time of perceiving opportunity (Mensah et al. 2021). Extensive knowledge and information about the market balance entrepreneurial decisions (Krizner 1979), but due to morbid uncertainty in the COVID-19 crisis, there 
seems to be a dearth of information at first sight. It can bring the nascent entrepreneurial journey to an end if entrepreneurs' OC is not strong enough.

However, in a different circumistance, having ample OC leads entrepreneurs to try to eliminate the uncertainty surrounding the opportunity. This uncertainty stems from unknown or limited information about the new circumstance and can be abated by accessibility to information (Mensah et al. 2021). Hence, by fueling the uncertainty, the COVID-19 crisis is increasing EPMA in nascent entrepreneurs who need to corroborate the feasibility and favorability of the opportunity.

At the same time, the risks, uncertainty, and volatility of the environment can be perceived as an opportunity (Nabi and Linan 2013) that might be welcomed by nascent entrepreneurs who are seeking possible high-quality opportunities caused by a crisis. Regarding IEO, the changes made by the COVID-19 pandemic require entrepreneurs to analyze the market owing to three main reasons. First, changes bring along uncertainty and entrepreneurs need to analyze the new market to ensure risk-taking makes functional and economic sense and the risk is still affordable. Second, entrepreneurs' innovativeness drives them to study the new market to discover avant-grade methods to meet new needs. Finally, entrepreneurs' proactiveness doesn't allow a passive wait-and-see approach, and as a result, they tend to analyze the new environment and changes. Entrepreneurs with higher IEO have a more optimistic view about the opportunity, its feasibility, and future auspicious outcomes. This intrepidity is rooted in the risk-taking and innovativeness of entrepreneurs. Therefore, entrepreneurs with higher IEO gain higher confidence in the opportunities in the time of the COVID-19 crisis.

\subsection{Theoretical contributions}

This study mainly contributes to applying and extending the theory of reasoned action (Fishbein and Ajzen 1975; Ajzen and Fishbein 1980; Ajzen 1991) in the field of entrepreneurship. It demonstrates that the EPMA as an impetus to entrepreneurial action depends on OC and IEO as its motivational factors. The introduction of EPMA to the field of entrepreneurship necessitates further research to expand our knowledge of this new concept. Little do scholars know about this new concept in relation to other already well-studied entrepreneurial constructs. In this study, we could elucidate the determinants and mechanisms of EPMA. It will provide entrepreneurship scholars with deeper insight into their future researches on EPMA, EO, and OC. Although having been discussed for a long, IEO has proved to be still a vibrant topic in entrepreneurship for scholars (Covin and Wlaes 2019). This study can add to the literature on this deep-rooted entrepreneurial construct.

We have not only investigated the determinants to the intention, i.e. EPMA, but also a mechanism to strengthen this intention. In other words, we have demonstrated that OC mediates the relationship between IEO and EPMA. This means that the impact of IEO goes through OC. An increase in IEO increases entrepreneurs' propensity to analyze the market, and this relation is mediated by the amount of confidence that entrepreneurs have in the perceived opportunity. The more IEO an entrepreneur has, the more confidence in the opportunity at hand they demonstrate. More 
confidence in the opportunity at hand leads to more propensity to analyze the market. So far, no other study has examined the relationship between IEO and EPMA and the mediating role of OC in this relationship.

Moreover, we have contributed to the early stage of entrepreneurial venturing research which is considered to be very crucial (Davidsson 2015; Dimov 2010; Shepherd et al. 2007a, b). This study is the first to investigate the moderating role of entrepreneurship entry mode in this conceptual model in the time of the COVID19 pandemic. Our results imply that in the process of new venture creation, opportunity entrepreneurs are the ones who demonstrate higher levels of IEO and more confidence in the opportunity, both of which lead to more propensity to analyze the market. In terms of business performance, previous studies show that compared to necessity entrepreneurs, opportunity entrepreneurs are more likely to create growthoriented ventures, make a larger profit and become dominant in the market (Block and Sandner 2009; GEM 2019; Fairlie and Fossen 2020). A credible justification might be that they have a stronger IEO and OC, and therefore have a higher propensity to analyze the market, which makes them closer to action and receiving early feedback from the real market, resulting in superior performance (Newbert et al. 2020).

Furthermore, our findings provide a during-crisis analysis rather than a post hoc reconstruction of events. This study focuses on nascent entrepreneurs to provide fresh insight into how a crisis like the COVID-19 can impact their decision-making process. It could provide a better understanding of the reason to start a business in the time of a crisis which, contrary to commonly held belief, is not mostly a sheer necessity. In this study, we try to address the lack of research evidence on decisionmaking incentives in a crisis time in the early stage of entrepreneurship.

\subsection{Practical implications}

Under highly uncertain circumstances, entrepreneurship is considered to be a key to successful business performance (Cho and Lee 2018; Hughes et al. 2018) and new opportunities for growth and change (Ferreira et al. 2019). In the time of crisis, entrepreneurship can be a means of thriving rather than surviving (Martiz et al. 2020), proving the importance of studying entrepreneurship to policymakers. Opportunity entrepreneurship is pro-cyclical and leads the cycle by two years, while necessity entrepreneurship is counter-cyclical and leads a one-year cycle (Fairlie and Fossen 2018; Koellinger and Thurikh 2012). As a result, not only can opportunity entrepreneurship alleviate economic problems in the crisis, but also can help boost the economy in the post-crisis condition and maintains more sustained economic growth. Therefore, while necessity entrepreneurship can work as a temporary remedy for the current economic problem with a low likelihood of success, opportunity entrepreneurship works as a long-term solution during and after crises.

Although the impacts of these two types of entrepreneurship are substantially different, they are stimulated by more or less similar impetuses (Mühlböck et al. 2018). For policymakers to promote opportunity entrepreneurship that affects economic growth positively and curtail necessity entrepreneurship, it is of great importance 
to avoid a one-size-fits-all approach (Borozan and Pfeifer 2014). In economic crises, policies offering business freedom with lowering the barriers become a classic panacea, whereas these policies can increase necessity entrepreneurs' share as they see fewer barriers. Despite the lower belief in the feasibility of the opportunity and lack of self-efficacy, they venture into entrepreneurship (Mühlböck et al. 2018). Therefore, resources and capital allocated to promoting entrepreneurship are also used by necessity entrepreneurs who do not stay in entrepreneurship long, can't create many jobs and their business activities are not fruitful or promising. Thus, the results of this study recommend having a specific support program for opportunity-driven entrepreneurs in times of crisis.

Moreover, this study has several implications for economic practitioners and policymakers. As entrepreneurs play a key role in helping economic condition in times of financial crises, it is also of crucial importance to policymakers to know how entrepreneurs think and make decisions in a time of crisis. This study helps to better comprehend how entrepreneurs' special traits -such as proactiveness, risk-taking, and innovativeness- lead to IEO and therefore result both in gaining more confidence in the perceived opportunity and increasing their tendency to study and analyze the market condition. The results of this study could contribute to more efficient planning in the occurrence of inevitable future crises. It could help those in authority to overcome the economic crisis by providing a better environment for opportunity entrepreneurs.

Innovative firms are at the heart of economic development, industrial evolution (Zwan et al. 2016), and entrepreneurship to get involved in product innovation (Darnihamedani and Hessels 2016). In this crisis, the COVID-19 crisis could prove that digital transformation is inevitable for almost all businesses. Without the help of electronic infrastructures, managing this critical situation would be impossible. Even traditionally-run businesses were forced to offer or use online services for advertisement or facilitating purchase. We strongly argue that, in the time of the COVID-19 pandemic and digital economy transformation, entrepreneurs need to have stronger beliefs to pursue an opportunity (Gopi and Ramayah 2007). In the case of opportunity entrepreneurs, policymakers have a critical role in supporting (opportunity) entrepreneurs to have higher confidence for EPMA regarding an opportunity.

Formal institutions (with legal rules and regulations) can impact opportunity entrepreneurship and entrepreneurs' confidence in their skills and can positively affect opportunity entrepreneurship, leading to the positive effect of opportunity entrepreneurship on economic growth (Aparicio et al. 2016). Opportunity entrepreneurship benefits from business freedom, labor freedom, and financial and educational capital (Fuentelsaz and Montero 2015). Therefore, it can imply that policymakers need to facilitate the entrepreneurial environment for opportunity entrepreneurs by providing them with these types of freedom and capital.

\subsection{Limitations and future studies}

The questionnaire was distributed in early 2020, which was the initial stage of the COVID-19 pandemic, and respondents might not have been severely affected by the 
condition by then. After the two-year effect of the COVID-19 pandemic, the result might be different if the study were replicated.

Although education doesn't seem to play an essential role in a noncrisis period (Verheul et al. 2012), in the time of crises, one of the main factors that differentiates necessity entrepreneurs from opportunity entrepreneurs is formal education (Muhlbock et al. 2013). This has not been investigated in our paper. Thus, it recommends that the prospective scholars investigate the impact of education on entrepreneurs' entry mode and its effect on our research model. The level of education has a positive relation with opportunity entrepreneurship and a negative relation with necessity entrepreneurship (Xavier-Oliveria et al. 2015). Opportunity entrepreneurs tend to be better educated (Stephan et al. 2015; Xavier-Oliveria et al. 2015). Therefore, their entry mode into entrepreneurship might have a stronger effect on the relationships mentioned.

Our paper has investigated two determinants of EPMA, namely IEO and OC. However, there are new trends that can encourage EPMA in a fast-changing time. Among those, machine learning and big data can have a significant impact on EPMA. Big data can help reduce uncertainty and is a valuable means for entrepreneurs to analyze the market more thoroughly. IEO helps entrepreneurs adopt more data-driven approaches to be able to keep pace with this fast-changing business environment. Prospective scholars are encouraged to investigate the impact of such trends in the proposed model.

In the time of economic recession and crises, there is a decrease in demand for products and services. Likewise, there is a fall in wealth which consequently makes financing even more difficult. On the other hand, in economic contraction, the cost of production (such as rent and compensation for wage and salary) decreases. We have seen the growth of new trends, i.e., cryptocurrency; Cryptocurrency has lifted borders and there is no governmental control over it. So, in times of crisis and economic recessions, perhaps our model can also be applied to discover entrepreneurial opportunities in cryptocurrency. Future studies may bring insights into this case.

\section{Conclusion}

This study proposed a new model based on the recently introduced concept, EPMA. Applying the theory of reasoned action, we could develop motivational factors of EPMA and examine the impact of entrepreneurial entry mode (necessity vs. opportunity) in the relation between the concepts of this study in the time of the COVID19 pandemic. History shows that crises are nationally and globally recurring, which indicates the importance of studying entrepreneurs' behavior in times of crises. The COVID-19 pandemic gave us the chance to study nascent entrepreneurs' decisionmaking process. In this study, we acquire a better understanding of nascent entrepreneurs' decision-making process to help facilitate entrepreneurship in future crises.

Data availability It is fully available upon request. 


\section{Declarations}

Conflict of interest The authors declare that have no conflict of interest.

\section{References}

Abreu M, Oner O, Brouwer A, van Leeuwen E (2019) Well-being effects of self-employment: a spatial inquiry. J Bus Ventur 34(4):589-607

Ajzen I (1991) The theory of planned behavior. Organ Behav Hum Decis Process 50(2):179-211

Ajzen I, Fishbein M (1980) Understanding attitudes and predicting social behavior. Prentice Hall, Englewood Cliffs, NJ

Ajzen I, Fishbein M (2005) The Influence of Attitudes on Behavior. In: Albarracín D, Johnson BT, Zanna MP (eds) The handbook of attitudes. Lawrence Erlbaum Associates Publishers, pp 173-221

Amoros JE, Cristie O (2011) Poverty and entrepreneurship in developing country. The Dynamics of entrepreneurship: evidence from global entrepreneurship monitor data. Oxford University Press, pp 209-230

Aparicio S, Urbano D, Audretsch D (2016) Institutional factors, opportunity entrepreneurship and economic growth: Panel data evidence. Technol Forecast Soc Chang 102:45-61

Arenius P, Minniti M (2005) Perceptual variables and nascent entrepreneurship. Small Bus Econ 24(3):233-247

Arrighetti A, Caricati L, Landini F, Monacelli N (2016) Entrepreneurial intention in the time of crisis: a field study. Int J Entrepreneurial Behav Res 22(6):835-859

Ashourizadeh S, Chavoushi ZH, Schøtt T (2014) People's confidence in innovation: a component of the entrepreneurial mindset, embedded in gender and culture, affecting entrepreneurial intention. Int $\mathrm{J}$ Entrep Small Bus 23(1-2):235-251

Autio E, Pathak S, Wennberg K (2013) Consequences of cultural practices for entrepreneurial behaviors. J Int Bus Stud 44(4):334-362

Bagozzi R, Dholakia U, Basuron S (2003) How effectful decisions get enacted: the motivating role of decision processes, desires and anticipated emotions. J Behav Decis Mak 16(4):273-295

Bateman S, Crant M (1993) The proactive component of organizational behavior. J Organ Behav 14(2):103-118

Baum JR, Wally S (2003) Strategic decision speed and firm performance. Strateg Manag J 24(11):1107-1129

Block J, Sandner P (2009) Necessity and opportunity entrepreneurs and their duration in self-employment: Evidence from German microdata. J Ind Compet Trade 9(2):117-137

Borozan D, Pfeifer S (2014) Exploring entrepreneurs' motivation: comparison of Croatia, European Postsocialist and developed countries. J Entrepreneurship 23(2):263-287

Boudreaux CJ, Nikolaev BN, Klein P (2019) Socio-cognitive traits and entrepreneurship: the moderating role of economic institutions. J Bus Ventur 34(1):178-196

Camerer C, Lovallo D (1999) Overconfidence and excess entry: an experimental approach. Am Econom Rev 89(1):306-318

Cannavale CH, Nadali IZ, (2018) Entrepreneurship across cultures. A BR approach. Transformative Business Strategies and New Patterns for Value Creation, 14-15.

Cassar G (2010) Are individuals entering self-employment overly optimistic? an empirical test of plans and projects on nascent entrepreneur expectations. Strateg Manag J 31(8):822-840. https://doi.org/ 10.1002/smj.833

Cassar G, Friedman H (2009) Does self-efficacy affect entrepreneurial investment? Strateg Entrep J 3(3):241-260. https://doi.org/10.1002/sej.73

Chavoushi ZH, Zali MR, Valliere D, Faghih N, Hejazi R, Dehkordi AM (2020) Entrepreneurial alertness: a systematic literature review. J Small Bus Entrepreneurship 33(2):123-52

Chen CC, Greene PG, Crick A (1998) Does entrepreneurial self-efficacy distinguish entrepreneurs from managers? J Bus Venturin 13(4):295-316

Chen HS, Mitchell RK, Brigham KH, Howell R, Steinbauer R (2018) Perceived psychological distance, construal processes, and abstractness of entrepreneurial action. J Bus Ventur 33(3):296-314. https://doi.org/10.1016/j.jbusvent.2018.01.001 
Cho YH, Lee JH (2018) Entrepreneurial orientation, entrepreneurial education and performance. Asia Pacific J Innov Entrepreneurship 12(2):124-134. https://doi.org/10.1108/APJIE-05-2018-0028

Covin JG, Wales WJ (2019) Crafting high-impact entrepreneurial orientation research: some suggested guidelines. Entrep Theory Pract 43(1):3-18. https://doi.org/10.1177/1042258718773181

Darnihamedani P, Hessels J (2016) Human capital as a driver of innovation among necessity-based etrepreneurs. Int J Entrepreneurship 14(1):1-23

Davidsson D (2015) Entrepreneurial opportunities and entrepreneurship nexus: a reconceptualization. J Bus Ventur 30(5):674-695

Dess GG, Lumpkin GT (2005) The role of entrepreneurial orientation in stimulating effective corporate entrepreneurship. Acad Manag Perspect 19(1):147-156

Dew N, Sarasathy S, Read S, Wiltbank R (2009) Affordable loss: behavioral economic aspects of the plunge decision. Strateg Entrep J 3(2):105-126. https://doi.org/10.1002/sej.66

Dimov D (2007a) From opportunity insight to opportunity intention: the importance of person-situation learning match. Entrep Theory Pract 31(4):561-583

Dimov D (2007b) Beyond the single person, single insight attribution in understanding entrepreneurial opportunities. Entrep Theory Pract 31(5):713-731

Dimov D (2010) Nascent entrepreneurs and venture emergence: opportunity confidence, human capital, and early planning. J Manage Stud 47(6):1123-1153

Dimov D, Pistrui P (2020) Recursive and discursive model of and for entrepreneurial action. Eur Manag Rev 17(1):267-277

Drabek TE (1987) Emergent structures. In: Dynes RR, De Marchi B, Pelanda C (eds) Sociology of disasters: Contribution of sociology to disaster research. Franco Angeli, Milan, pp 190-259

Drabek TE, McEntire DA (2002) Emergent phenomena and multi-organizational coordination in disasters: lessons from the research literature. Int J Mass Emerg Disasters 20(2):197-224

Elifneh YW (2015) What triggers entrepreneurship? the necessity/opportunity dichotomy: a retrospection. J Poverty, Invest Develop 15(15):22-7

Emami A (2020) Effective causes in transferring intention to action in entrepreneurial value creation. J Entrepreneurship Develop 12(3):321-339. https://doi.org/10.29059/JED.2019.290487.653146

Emami A, Dimov D (2017) Degree of innovation and entrepreneurs' intention to create value: a comparative study of novice entrepreneurs. Eurasian Bus Rev 7:161-182

Emami A, Khajeheian D (2019) Social norms and entrepreneurial action: the mediating role of opportunity confidence. Sustainability $11(1): 1-18$

Emami A, Klein PG (2020) The entrepreneurial propensity for market analysis and the intention-action gap. Int J Entrep Ventur 12(3):303-320

Fairlie RW, Fossen FM, (2018) Opportunity versus necessity entrepreneurship: Two components of business creation, SOEP papers in multidisciplinary panel data research, No.959, Deutsches Institut fur Wirtschaftsforschung (DIW), Berlin

Fairlie RW, Fossen FM (2020) Defining opportunity versus necessity entrepreneurship: Two components of business creation. SSRN Electron J. https://doi.org/10.2139/ssrn.3132357

Ferraris A, Santoro G, Pellicelli AC (2020) Openness of public governments in Smart cities: removing the barriers for innovation and entrepreneurship. Int Entrepreneurship Manag Journal 16(4):1259-1280

Ferreira FA, Marques CS, Bento P, Ferreira JJ, Jalali MS (2015) Operationalizing and measuring individual entrepreneurial orientation using cognitive mapping and MCDA techniques. J Bus Res 68(12):2691-2702

Ferreira JJ, Fernandes CI, Kraus S (2019) Entrepreneurship research: mapping intellectual structures and research trends. RMS 13(1):181-205

Fishbein M, Ajzen I (1975) Belief, attitude, intention, and behavior: An introduction to theory and research. Addison-Wesley, Reading, Mass.

Fishbein M, Ajzen I, Albarracin D, Hornik R (2007) A reasoned action approach: Some issues, questions, and clarifications. Predict change health behav: Apply reason action approach 13:281-295

Fuentelsaz L, Montero J (2015) What makes some entrepreneurs more innovative? Univ Bus Rev 47:14-31

Gaglio CM, Katz JR (2001) The psychological basis of opportunity identification: entrepreneurial alertness. Small Bus Econ 16(2):95-111

Galbreath J, Lucianetti L, Thomas B, Tisch D (2020) Entrepreneurial orientation and firm performance in Italian firms: The moderating role of competitive strategy. Int J Entrep Behav Res 26(4):629-646

GDA (Global Data Analysis) (2020) Coronavirus (COVID-19) executive briefing. Global Data 
Glick M (2017) Believing is seeing: confirmation bias. J Am Dent Assoc 148(3):131-132

Global Entrepreneurship Monitor (GEM) (2018) Global Report. https://www.gemconsortium.org/

Global Entrepreneurship Monitor (GEM), 2019/2020 Global Report. https://www.gemconsortium.org/

González-Pernía JL, Guerrero M, Jung A, Pena-Legazkue, (2018) Economic recession shake-out and entrepreneurship: Evidence from spain. BRQ Bus Res Q 21:15-167

Gopi M, Ramayah T (2007) Applicability of theory of planned behavior in predicting intention to trade online: some evidence from a developing country. Int J Emerg Mark. 2(4):348-360

Gruger M, Kim SM, Brinckmann J (2015) What is an attractive business opportunity? an epirical study of opportunity evaluation decisions by technologists, managers, and entrepreneurs. Strateg Entrep J 9:205-225

Hayward ML, Shepherd DA, Griffin D (2006) A hubris theory of entrepreneurship. Manage Sci 52(2):160-172

Heckhausen J (2007) The motivation-volition divide and its resolution in action-phase models of behavioral and developmental regulation. Res Hum Dev 4(3-4):163-180

Howard MC (2020) Using the HEXACO-100 to measure individual entrepreneurial orientation: introducing the HEXACO-IEO. J Bus Ventur Insights 13:e00163

Hughes M, Rigtering JC, Covin JG, Bouncken RB, Kraus S (2018) Innovative behaviour, trust and perceived workplace performance. Br J Manag 29(4):750-768

Hulin C, Netemeyer R, Cudeck R (2001) Can a reliability coefficient be too high? J Consum Psychol 10:55-58

Ionescu-Somers, A. (2020). Covid-19: Lessons from past crises point to a long and hopeful road for entrepreneurs. Times of Entrepreneurship GEM 2020.

IPRCIRI (2020). On dealing with corona outbreaks - Assessing the macroeconomic dimensions of the corona virus outbreak, Islamic Parliament Research Center of The Islamic Republic of Iran.

Javidan M, Dastmalchian A (2003) Culture and leadership in Iran: the land of individual achievers, strong family ties and powerful elite. Acad Manag Exec 17(4):127-142

Jelence L, Pisapia J, Ivanusic N (2015) Demographic variables influencing individual entrepreneurial orientation and strategic thinking capability. In: Proceeding of 10th international scientific conference on economic and social development

Joardar A, Wu S (2011) Examining the dual forces of individual entrepreneurial orientation and liability of foreignness on international entrepreneurs. Can J Adm Sci 28(3):328-340

Kaish S, Gilad B (1991) Characteristics of opportunities search of entrepreneurs versus executives: sources, interests, general alertness. J Bus Ventur 6(1):45-61

Kapucu N, Augustin ME, Garayev V (2009) Interstate partnership in emergency management: emergency management assistance compact in response to catastrophic disasters. Public Adm Rev 69:297-313

Keh HT, Foo MD, Lim BC (2002) Opportunity evaluation under risky conditions: the cognitive processes of entrepreneurs. Entrep Theory Pract 27(2):125-148

Koellinger PD, Thurik AR (2012) Entrepreneurship and the business cycle. Rev Econ Stat 94(4):287-306

Kollman T, Stockman Ch, Meves Y, Kensbock JM (2017) When members of entrepreneurial team differ: linking diversity in individual-level entrepreneurial orientation to team performance. Small Bus Econ 48:843-859

Kollmann T, Christofor J, Kuckertz A (2007) Explaining individual entrepreneurial orientation: conceptualisation of a cross-cultural research framework. Int J Entrep Small Bus 4(3):325-340

Krizner IM (1979) Perception, opportunity, and profit. Studies in the theory of entrepreneurship. University of Chicago Press, Chaicago

Kruger N, Sussan F (2017) Person-level entrepreneurial orientation: clues to the 'entrepreneurial mindset'? International Journal of Business and Globallisation 18(3):382-395

Lee MS, Peterson SJ (2000) Culture, entrepreneurial orientation, and global competitiveness. J World Bus 35(4):401-416

Lumpkin GT, Dess GG (1996) Clarifying the entrepreneurial orientation construct and linking it to performance. Acad Manag Rev 21(1):135-172

Macko A, Tyszka T (2009) Entrepreneurship and Risk Taking. Appl Psychol 58(3):469-487. https://doi. org/10.1111/j.1464-0597.2009.00402.x

Mair J, Marti I, Ganly K (2007) Institutional void as space of opportunity. Post-Print hal-02311879, HAL

Martiz A, Pereneyi A, Waal G, Bck Ch (2020) Entrepreneurship as the unsung hero during the current Covid-19 economic crisis: Australian perspective. Sustainability 12(11):4612 
Massar K, Nubold A, Droon RV, Schelleman-Offermans K (2020) Picking up the reigns: the crucial role of psychological capital in the transition from long-term unemployment to entrepreneurship. Entrepreneurial Small Bus Stressors, Exp Stress, Well-Being 18:147-170. https://doi.org/10.1108/ S1479-355520200000018007

McCann BT, Vroom G (2015) Opportunity evaluation and changing beliefs during nascent entrepreneurial process. Int Small Bus J 33(6):612-637

McMullen JS, Shepherd DA (2006) Entrepreneurial action and the role of uncertainty in the theory of entrepreneur. Acad Manag Rev 31:132-152

Mensah EK, Asamoah LA, Jafari-Sadeghi V (2021) Entrepreneurial opportunity decisions under uncertainty: recognizing the complementing role of personality trait and cognitive skills. J Entrepreneurship, Manage Innov 17(1):25-55. https://doi.org/10.7341/20211711

Mitchell JR, Shepherd DA (2010) To think own self be true: images of self, images of opportunity, and entrepreneurial action. J Bus Ventur 25(1):138-154

Mitchell RK, Smith B, Sewright KW, Morse EA (2000) Cross-cultural cognition the venture creation decision. Acad Manag J 43(5):974-993

Moradi M, Imanipour N, Arasti Z, Mohammadkazemi R (2020) Poverty and entrepreneurship: a systematic review of poverty-related issues discussed in entrepreneurship literature. World Rev Entrepreneurship, Manag Sustain Develop 16(2):125

Mühlböck M, Warmuth JR, Holienka M, Kittel B (2018) Desperate entrepreneurs: No opportunities, no skills. Int Entrepreneurship Manag J 14(4):975-997

Nabi G, Linan F (2013) Considering business start-up in recession time. The role of risk perception and economic context in shaping the entrepreneurial intent. Int $\mathbf{J}$ Entrepreneurial Behav Res 19(6):633-655

Newbert SL, Tornikoski ET, Augugliaro J (2020) To get out of the building or not? that is the question: the benefits (and costs) of customer involvement during the startup process. J Bus Ventur Insights 14:00209. https://doi.org/10.1016/j.jbvi.2020.e00209

Nieuwenhuizen C, Groenewald D (2006) Level of creativity and risk among successful entrepreneurs. South Afr Bus Rev 10(1):70-90

Packard MD (2017) Where did interpretivism go in the theory of entrepreneurship? J Bus Ventur 32(5):536-549

Packard MD, Clark BB, Klein PG (2017) Uncertainty types and transitions in the entrepreneurial process. Organ Sci 28(5):840-856

Pinillos MJ, Reyes L (2011) Relationship between individualist-collectivist culture and entrepreneurial activity: evidence from Global Entrepreneurship Monitor data. Small Bus Economist 37(1):23-37

Pittino D, Visintin F, Lauto G (2017) A configurational analysis of the antecedents of entrepreneurial orientation. Eur Manag J 35:224-237

Reynolds PD, Hay M, Bygrave WD, Camp MS, Autio E (2000) Global entrepreneurship monitor: 2000 executive report. Kauffman Center Entrepreneurial Leadership Ewing Kaufman Found. https://doi. org/10.13140/RG.2.1.3549.9043

Schneider SK (1992) Governmental response to disasters: The conflict between bureaucratic procedure and emergent norms. Public Adm Rev 52(2):135-145

Schneider SK (2008) Who's to blame? (Mis) perception of the intergovernmental response to disaster. J Federalism 38(4):715-738

Shane S (2000) Prior knowledge and the discovery of entrepreneurial opportunities. Organ Sci 11(4):448-469

Shane S (2003) A general theory of entrepreneurship: the individual-opportunity nexus. Int Small Bus J: Res Entrepreneurship 22(2):206-216

Sharma L (2019) A systematic review of the concept of entrepreneurial alertness. J Entrepreneurship Emerg Econom 11(2):217-233

Shepherd DA, McMullen JS, Jennings PD (2007a) The formation of opportunity beliefs: overcoming ignorance and reducing doubt. Strateg Entrep J 1:75-95

Shepherd DA (2020) COVID 19 and entrepreneurship: time to pivot? J Manag Studies Wiley Blackwell 57(8):1750-1753. https://doi.org/10.1111/joms.12633

Shepherd DA, McMullen JS, Devereaux J (2007b) The formation of opportunity beliefs: overcoming ignorance and reducing doubt. Strateg Entrep J 1(1-2):75-95

Stephan U, Hart M, Mickiewicz T, Drews CC (2015) Understanding motivations for entrepreneurship, BIS Research paper No. 212, http://eprints.aston.ac.uk/25296/1/Understanding_motivations_for_ etrepreneurship.pdf 
Stine RA (1995) Graphical interpretation of variance inflation factors. Am Stat 49(1):53-56

Taherinia M, Hasanvand A (2020) Economic consequences of Covid-19 disease on the Iranian economy With an emphasis on employment. Quart J Nurs Manag 9(3):43-58

Tang J, Kacmar KM, Busenitz L (2012) Entrepreneurial alertness in the pursuit of new opportunities. J Bus Ventur 27:77-94. https://doi.org/10.1016/j.jbusvent.2010.07.001

Valdez ME, Richard J (2013) Institutional determinant of macro-level entrepreneurship. Entrep Theory Pract 37(5):1149-1175

Verheul I, Thurikh R, Grilo I, Zwan P (2012) Explaining preferences and actual involvement in selfemployment: gender and entrepreneurial personality. J Econ Psychol 33:325-341

Vilanova L, Vitanova I (2020) Unwrapping opportunity confidence: how do different types of feasibility beliefs affect venture emergence? Small Bus Econom 55:215-236. https://doi.org/10.1007/ s11187-019-00159-4

Virick M, Basu A, Rogers A (2015) Antecedents of entrepreneurial intention among laid-off individuals: a cognitive appraisal approach. J Small Bus Manage 53(2):450-468

Walter M (2006) Social science methods: an Australian perspective. Oxford University Press, Oxford, New York

Williams C, Round J, Rodgers P (2009) Evaluating the motives of informal entrepreneurs: some lessons from Ukraine. J Dev Entrep 14(01):59-71

Williams DW, Wood MS (2015) Rule-based reasoning for understanding opportunity evaluation. Acad Manag Perspect 29(2):218-236. https://doi.org/10.3390/su12114612

Wood MS (2017) Misgivings about dismantling the opportunity construct. J Bus Ventur Insights 7:21-25

Xavier-Oliveria E, Laplume AO, Pathak S (2015) What motivates entrepreneurial entry under economic inequality? the role of human and financial capital. Human Relations 68(7):1183-1207

Zhao D, Smallbone D (2019) What affects nascent entrepreneurs' proactiveness. Asia Pac Manag Rev 24:318-326

Zhao X, Li H, Rauch A (2012) Cross country differences in entrepreneurial activity: the role of cultural practice and national wealth. Front Bus Res China 6(4):447-474

Zissimopoulos J, Karoly LA (2010) Employment and self-employment in the wake of Hurricane Katrina. Demography 47:345-367. https://doi.org/10.1353/dem.0.0099

Zwan P, Thurik R, Verheul I, Hessels J (2016) Factors influencing the entrepreneurial engagement of opportunity and necessity entrepreneurs. Eurasian Bus Rev 6(3):273-295

Publisher's Note Springer Nature remains neutral with regard to jurisdictional claims in published maps and institutional affiliations.

\section{Authors and Affiliations}

\section{Amir Emami ${ }^{1}{ }^{\circledR}$. Shayegheh Ashourizadeh ${ }^{2}\left[\right.$ - Shima Sheikhi ${ }^{1}$. Gadaf Rexhepi ${ }^{3}$ (1)}

Shayegheh Ashourizadeh

Shaya.ashouri@wur.nl

Shima Sheikhi

Sheikhi.shima@gmail.com

Gadaf Rexhepi

g.rexhepi@seeu.edu.mk

1 Faculty of Management, Kharazmi University, Tehran, Iran

2 Business Management and Organization group, Wageningen University and Research, Wageningen, Netherlands

3 Faculty of Business and Administration and MVDSI, South East European University, Tetovo, North Macedonia 